\title{
International Journal of Sciences
}

Research Article

Volume 11 - February 2022 (02)

\section{Determination of Pesticide Residues in Yam (Dioscorea rotundata) Tubers Grown with Perfect Killer Insecticide, and their Effects on Growth Indices and Proximate Composition}

\author{
Hannaniah Shenia Zephaniah ${ }^{1}$, Yusufu Dawoye ${ }^{2}$, Kingsley Audu ${ }^{3}$, \\ Stephen Olaide Aremu ${ }^{4,5}$
}

\author{
${ }^{1}$ Department of Biochemistry, University of Nigeria, Nsukka, Enugu State, Nigeria \\ ${ }^{2}$ Department of Biological Sciences, Federal University Wukari, Taraba State, Nigeria \\ ${ }^{3}$ Department of Science, Laboratory and Technology, Federal Polytechnic Bali, Taraba State, Nigeria \\ ${ }^{4}$ Department of Microbiology, Federal University of Agriculture, Makurdi, Benue State, Nigeria \\ ${ }^{5}$ Faculty of General Medicine, Siberian State Medical University, Tomsk, Russian Federation
}

Abstract: Recent advancement in agriculture and the need for higher production to combat hunger and poverty has led to increased use of pesticides. Perfect killer insecticide is a highly used pesticide in some regions of Nigeria in yam production that is labeled to contain only chlorpyrifos (20\%) as active component. Current studies have reported the accumulation of various pesticides in food products which have raised many health issues. In this study, seedlings of yam tubers (D. rotundata) were treated with perfect killer insecticide prior to planting. Growth parameters, chlorophylls content and proximate composition were determined. A total of eleven (11) residues were detected in the treated tubers while only three (3) were found in the control. The pesticide had no significant effect on chlorophylls. The results suggest that Perfect killer insecticide is a combination of different pesticides; and as such, consumption of crops grown with it is unsafe.

Keywords: Pesticide, Perfect Killer, Insecticide, Residues, Active Components, Yam

\section{Introduction}

Yam is a tropical tuber crop that is cultivated in Africa, Asia South America, the Caribbean, as well as the South Pacific islands. After cassava yam is the second most important tuber crop in African countries including Nigeria, Ghana, Côte d'Ivoire (Ivory Coast), Benin and Togo, where it plays an essential role in the nutritional and sociocultural life of more than 60 million people (IITA, 2009; Oguntade, 2010; Andres et al., 2017). It is usually prepared and consumed in several forms such as boiled, fried, "Amala", pounded as well as pottage. Many yam belt areas in Nigeria continuously proclaimed "yam is food and food is yam"; and some family rural dwellers, where yams are grown, eat it all day round, arguably because yams are the only available food, especially during the harvest season (Maikasuwa and Ala, 2013; Verter and Bečvařova, 2015). Yam production is faced with several challenges including weeds, beetles, insects and microbial attacks. Hence, the large scale production of yam in Nigeria has been achieved over the years through the use of pesticides (especially insecticides and herbicides), in addition to fertilizers, to optimize yields in order to combat hunger and poverty. Pesticides, generally are toxic chemical substances that when applied on plants leave traces in the crop products which can be considered to be of toxicological significance (IPCS, 2012), to both the plants and the consumers. It is currently reported that there is no group in the human population that is completely unexposed to pesticides (Ki-Hyun et al., 2017).

Pesticide application has been reported to confer serious adverse effects on plants. These effects range from germination of seeds to growth of the plants, which may lead to alteration in the biochemical, physiological and different enzymatic and nonenzymatic antioxidants. As a result of this alteration the yield of these exposed crops are ultimately affected. Pesticides when applied leave traces of residues in tubers, vegetables, fruits etc. (Parween et al., 2016). Studies have reported that short and long term exposure of human to pesticides through inhalation, ingestion (of contaminated drinks and foods) or dermal contact are associated with several health challenges such as: dizziness, abdominal pain, birth defects, teratogenic effects, cancer, gene mutation, blood disorders, nerve disorders, endocrine disruption, and reproduction defects (Ki-Hyun et al., 2017; Yadav and Devi, 2017).

Several previous studies have revealed the presence of many pesticide residues including aldrin, dichloran, dieldrin, endrin, endosulfan, heptachlor epoxide, dichlorodiphenyltrichloroethane (DDT), lindane, fenpropimorph, cadusafos and fenitrothion in food products such as cereal grains, yam, rice, beans 
etc. (Adeyeye and Osibanjo, 1999; Ogah et al., 2011; Wumbei et al., 2018).

Accumulated pesticide residues in food products have been associated with a broad variety of human health hazards, ranging from short-term to long-term toxic effects (Grewal et al., 2017). Perfect killer insecticide is among the major pesticides used in Wukari area of Taraba State in the production of yam. It is used in the treatment of yam seedlings during planting to combat beetles attacks. It is labelled by the manufacturer to contain $20 \%$ chlorpyrifos; however, it is suspected to contain other pesticide active components due to its broader spectrum of activity. Therefore, this study was carried out to evaluate the presence of pesticide residues in yam tubers treated with Perfect killer insecticide and their possible toxicological effects on the plants, which could as well pose risks to the consumers.

\section{Materials and Methods}

Experimental Site: The experimental farm was set up in a virgin garden at the University of Nigeria Nsukka Staff Quarter (718 Ukuta Close), Enugu State Nigeria. It lies between longitude 6051 ' $30.5 \mathrm{~N}$ ” and latitude 7o $24^{\prime} 02.7^{\prime \prime} \mathrm{E}$ of the equator.

Perfect killer (chlorpyrifos 20\% EC) insecticide (produced by Nantong Jinling Agricultural chemical Co. LTD) was purchased from an agrochemical store in Wukari.

\section{Experimental Design}

Twenty four (24) tubers of white yam were divided into two (2) groups of fourteen (12) tubers each and treated as follows:

Group 1:Control (untreated)

Group 2: Treated (with 2\% Perfect killer insecticide solution)

The yam tubers were washed in $2 \%$ perfect killer insecticide solution before planting on the prepared mounds (heaps). Germination rate was determined by observing the heaps closely for the first sprouts. Morphological (growth) parameters were measured two (2) months after first germination, after which fresh leaves were collected for chlorophyll analysis. Tubers were harvested after seven (7) months of planting when all the leaves have dried. The harvested tubers were prepared for proximate and residual analyses.

\section{Chemical}

All chemicals used in this study were of analytical grade and were obtained from Merck (Germany), May and Baker (England), Sigma Chemical Company (USA).

\section{Plant Materials}

Yam seedlings of $D$. rotundata (locally called 'aloshi') with mean weight of $159.02-172.17 \mathrm{~g}$ were obtained from Wukari International Yam market and planted in a virgin garden at the University of Nigeria Staff Quarters (718 Utuka Close). Plant leaves were collected from the experimental farm for chlorophyll contents analysis, and harvested tubers were selected for proximate and pesticide residual analyses.

\section{Chemical Analyses}

Study on the morphological parameters (including leaf size, stem circumference and number of branches) were carried as described by Osiru and Hahn (1994).

Estimation of chlorophyll a, b and total chlorophyll contents of fresh leaves was performed as described by Arnon (1949).

Pesticide active components of Perfect Killer Insecticide were determined using Gas Chromatography-Mass Spectroscopy (GC-MS) as described by standard method of AOAC (1990).

Pesticide residues of yam tubers were determined using Gas Chromatography-Electron Capture Detector (GC-ECD) as described by standard method of AOAC (1990).

\section{Soxhlet Extraction Method}

Selected tubers from both experimental groups were chopped into small pieces and dried in an air convention oven at $60^{\circ} \mathrm{C}$ for 72 hours (Lape and Treche, 1994). The dried chips were milled into fine flour and used for residual analysis immediately. Exactly $10 \mathrm{~g}$ of the homogenate was mixed with $60 \mathrm{~g}$ of anhydrous sodium sulphate in agate to absorb moisture. Extraction was carried out with $300 \mathrm{ml}$ of $\mathrm{n}$ hexane for 24hrs. Crude extract obtained was evaporated using a rotatory vacuum evaporator at $40^{\circ} \mathrm{C}$, just to dryness.

\section{Sample Preparation for GC Analysis}

About $1 \mathrm{ml}$ of the filtered residue was dissolved in $50 \mathrm{ml}$ of chloroform and transferred to a $100 \mathrm{ml}$ volumetric flask and diluted to the mark. The chloroform was evaporated at room temperature. Then $1 \mathrm{ml}$ of reagent $(20 \mathrm{vol} \%$ benzene and $55 \mathrm{vol} \%$ methanol) was added to the flask, sealed and heated at $40 \mathrm{oC}$ in a water bath for 10minutes. After heating, organic sample was extracted with hexane and water, so that the final mixture of the reagent, hexane and water was in a proportion of 1:1:1 (i.e. $1 \mathrm{ml}$ each of hexane and water was added to the reaction mixture). The mixture was shaken vigorously by hand for 2minutes, and centrifuged to break the stable emulsion that was formed. About half of the top hexane phase was transferred to a small test tube for 
Determination of Pesticide Residues in Yam (Dioscorea rotundata) Tubers Grown with Perfect Killer Insecticide, and their Effects on Growth Indices and Proximate Composition

injection (with carefulness so that only the organic layer was removed). $1 \mu \mathrm{L}$ of the prepared sample was injected into the column of the set up and ready GCECD using appropriate injection technique.

\section{Statistical Analysis}

Data obtained from this experimental study were analyzed using independent student t-test. The results were expressed as mean $\pm \mathrm{SD}$, p values $<0.05$ were considered to be statistically significant at $95 \%$ confidence interval. The statistical package used was the SPSS version 20.

\section{Result and Discussion}

GC-MS revealed that perfect killer insecticide contains three (3) active chemicals (Table 1) including 2,2-dichlorovinyldimethylphosphate (dichlorvos or DDVP at 71.53\%); O,O-diethyl O3,5,6-trichloropyridin-2-yl phosphorothioate (Chlorpyrifos at 6.54\%); and 1,1'-(2,2dichloroethane-1,1-diyl)bis(4-chlorobenzene) (DDD at $4.58 \%$ ). This is contrary to the manufacturer's label that chlorpyrifos is the only active component of perfect killer insecticide at $20 \%$. This result indicates that Perfect killer insecticide is a combination of different pesticides with probable different modes of action, which according to Babu et al. (2010) will have broader spectrum of activity with better efficacy; and consequently will exhibits a different toxicological profile compared with toxicity of the individual pesticides. Although combination of pesticides is seemingly more effective in combating pest resistance, this combination poses a new challenge since the resultant effects of such interactions are unknown (Banke et al., 2014). This means that farmers who apply this chemical are at high risk of exposure to DDVP, chlorpyrifos and DDD not only by consuming contaminated foods but also through inhalation and dermal absorption due to improper body protection, hence may result to various pesticide-associated health challenges.

Table 1: The active components of Perfect Killer Insecticide

\begin{tabular}{lll}
\hline Table 1: The active components of Perfect Killer Insecticide & Common pesticide Name & $\begin{array}{l}\text { Area \% } \\
\text { (Abundance) }\end{array}$ \\
\hline 2,2-dichlorovinyl dimethylphosphate & & 71.63 \\
\hline 1,1'-(2,2-dichloroethane-1,1-diyl)bis(4-chlorobenzene) & Dichlorvos or DDVP & 4.58 \\
\hline O,O-diethyl O-3,5,6-trichloropyridin-2-yl phosphorothioate & DDD (DDT) & 6.54 \\
\hline
\end{tabular}

The result of germination rate shows that five (5) yam sprouted on the treated group after 24days of planting, whereas only one (1) sprouts on the control after 27days. This indicates enhanced germination by the pesticide. This implies that the pesticide increased germination rate of the tubers. The result is similar to that reported by Claudius-Cole et al. (2017) that yam setts treated with pesticides (fungicide-insecticide mixture) sprouted better than the untreated. Similarly, Moore and Kroger (2010) found that an insecticide diazinon proved better germination $(85 \%)$ than fipronil $(76 \%)$ and the control $(80 \%)$ of rice seed. On the contrary, Rajashekar et al. (2012) found that germination of Zea mays L. was maximum (95\%) in control compared to treated seeds with pendimethalin which indicated a drastic decreased in germination rate. However, as at the time of this study no single study was found which elucidates the mechanism by which pesticides (both insecticide and herbicide) reduce or increase germination rates of seeds.

The result of the growth indices of this study indicated a significant decrease in leaf sizes of treated plants as compared to the control whereas the number of branches of treated plants decreased significantly and stem circumference showed no significant different (Table 2).

Table 2: The Result of the Morphological parameters of $\boldsymbol{D}$. rotundata

\begin{tabular}{cccc}
\hline & \multicolumn{3}{c}{ Parameters } \\
\cline { 2 - 4 } Groups & Leaf Size $(\mathbf{c m})$ & Stem Circumference $(\mathbf{c m})$ & Number of Branches \\
\hline Control & $31.40 \pm 4.52$ & $3.13 \pm 0.73$ & $22.00 \pm 13.71$ \\
Test & $18.72 \pm 4.60$ & $3.98 \pm 0.88$ & $9.17 \pm 4.45$ \\
\hline The results are expressed as mean \pm standard deviation; $\mathrm{n}=6$. & &
\end{tabular}

The results are expressed as mean \pm standard deviation; $\mathrm{n}=6$.

Contrary to the result of Parween et al. (2011b) which showed that chlorpyrifos has a significant increase in the height, number of branches, leaves per plant, total leaf area, plant biomass of Vigna radiata L.; this could be as a result of blockage of plants photosynthetic electron transport and photosystem II (PSII) reaction by the pesticide as reported by Barry et al. (1990) and Fuerst and Norman (1991).

The harvested tubers were stored for a period of five
(5) months. It was observed that only two (2) tubers rotted on the treated side, while the remaining tubers in this group had healthy sprouts (Fig. 1A); whereas, on the other side (untreated), five (5) tubers rotted, while some of the remaining tubers had unhealthy sprouts and others had no sprouts (Fig.1B). Also, the treated tubers were observed to be free from fungi (molds) growth; whereas molds were observed on the untreated tubers. It can be suggested that the present of the residues of Perfect Killer Insecticide in the 
tubers confer protective measures, thereby preventing it from environmental and microbial attacks. So also it regulates the physiological architecture of the tubers leading to the breakage of dormancy, thereby enhancing germination. On the other hand, environmental and microbial agents have affects on vital biochemical components of the untreated tubers which in turn resulted to hindering/delaying in germination.

A)

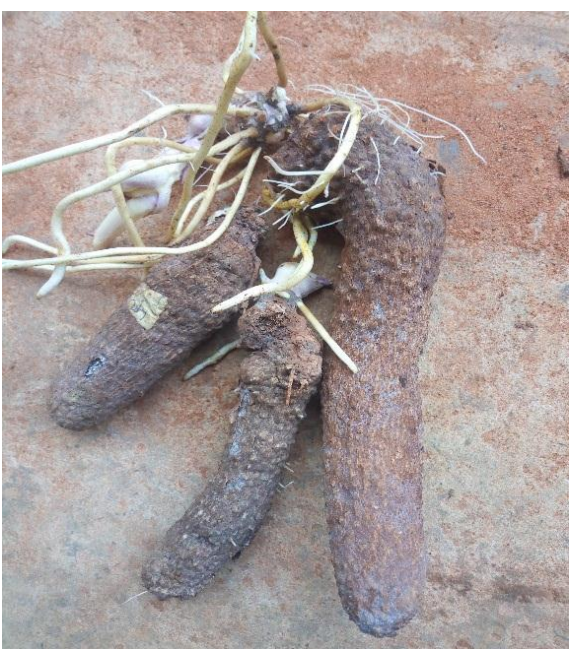

B)

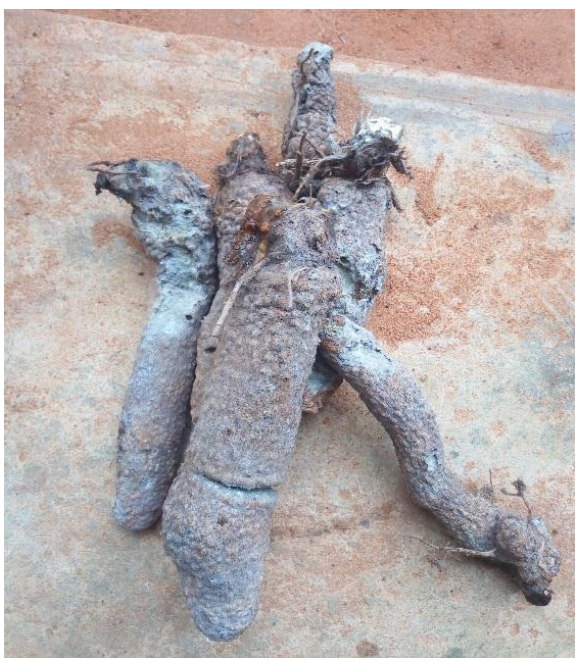

Figure 1: Shelf life of yam tubers treated with perfect killer insecticide. $\mathrm{A}=$ treated tubers; $\mathrm{B}=$ untreated tubers.

The observation of fungal growth is in concordance with the results of previous studies by Coursey (1967) and Aboagye-Nuamah et al. (2005). However, Wumbei et al. (2019) investigated the effect of herbicide (glyphosate) use on the yield and shelf life of yams and found that glyphosate has no significant effects on yam yields.

In this study, chlorophyll a, b and total chlorophyll were found to be statistically insignificant $(p>0.05)$ (Table 3). This means that the pesticide has no traceable effects on the photosynthetic apparatus which could lead to either increase or decrease in photosynthesis efficiency of yam plants. This observation is in agreement with the findings of Parween et al. (2011). They observed that chlorophyll a, b, total chlorophyll and Carotene contents were the same (highest) in control as well as chlorpyrifos treated plants at flowering stage followed by preflowering and postflowering stages of legume (Vigna radiata L.). However, the result disagreed with the report of Vishnu et al. (2015) and Rehab (2016) that several pesticides including Chlorosan (chlorpyrifos 48\%EC), Malathion (57\% EC), Endosulfan, Rezolex $\mathrm{T}(50 \% \mathrm{WP})$, etc. are extremely effective in reducing chlorophyll ' $a$ ', 'b' and total chlorophyll and carotene contents in maize, tomatoes and Vicia faba. However, the difference in the results could be due to the involvement of various factors as suggested by Ki-Hyun et al. (2017) such as period and level of exposure, type of pesticide (regarding toxicity and persistence) and environmental

Table 3: The result of chlorophyll content of D.rotundata

\begin{tabular}{cccc}
\hline & & Parameters & \\
\cline { 2 - 4 } Groups & Chlorophyll a & Chlorophyll b & Chlorophyll total \\
Control & $13.62 \pm 5.15$ & $10.55 \pm 5.43$ & $24.16 \pm 10.11$ \\
Test & $18.03 \pm 3.30$ & $11.22 \pm 0.86$ & $29.25 \pm 3.11$ \\
\hline
\end{tabular}

Result expressed as mean \pm standard deviation; $\mathrm{n}=3$.

Result of proximate composition showed that ash content $(4.85 \pm 0.23)$ and crude fat $(2.73 \pm 0.22)$ are significantly higher in the treated group compared to the control, with the content of fibre $(0.28 \pm 0.06)$ being significantly lower; whereas other compositions; moisture, proteins and carbohydrate were not significant (Table 4). In both the treated and control, moisture, fibre and carbohydrate contents were comparably lower than those reported by Baah et al. (2009) in untreated yam tubers; whereas ash, proteins and fat contents are lower. 
Determination of Pesticide Residues in Yam (Dioscorea rotundata) Tubers Grown with Perfect Killer Insecticide, and their Effects on Growth Indices and Proximate Composition

Table 4: The result of proximate composition of $D$. rotundata

\begin{tabular}{ccccccc}
\hline & \multicolumn{5}{c}{ Parameters } \\
\cline { 2 - 6 } Groups & Moisture & Ash & Fibre & Fat & Proteins \\
\hline Control & $25.61 \pm 0.58$ & $4.34 \pm 0.14$ & $1.18 \pm 0.14$ & $2.07 \pm 0.10$ & $8.17 \pm 0.20$ & Carbohydrate \\
Test & $26.57 \pm 0.90$ & $4.85 \pm 0.23$ & $0.28 \pm 0.06$ & $2.73 \pm 0.22$ & $7.93 \pm 0.40$ & $57.19 \pm 0.46$ \\
\hline
\end{tabular}

Results are represented in mean \pm standard deviation; $\mathrm{n}=3$.

Several pesticide residues have been reported to exhibit bioaccumulation in plants which could build up to harmful levels in the body of humans and animals that feed on them. The residues detected on a particular food item will depend on which pesticides have been used and how persistent they are.

In this study, a total of eleven (11) pesticides residues (both insecticides and herbicides) were detected (Table 5): nine (9) insecticides, two (2) herbicides. The result indicated that dichlorvos has the highest value $(9.615 \mathrm{mg} / \mathrm{kg}), \quad$ followed by dichlorodiphenyldichloroethane (DDD)
$(0.333 \mathrm{mg} / \mathrm{kg})$, paraquat $(0.298 \mathrm{mg} / \mathrm{kg})$, chlordane $(0.111 \mathrm{mg} / \mathrm{kg})$, chlorpyrifos $(0.072 \mathrm{mg} / \mathrm{kg})$, transnonachlor $(0.070 \mathrm{mg} / \mathrm{kg})$ and emamectin $(0.016 \mathrm{mg} / \mathrm{kg})$ which are all higher than the European Commission maximum residue limit (EU MRL); whereas, the rest of the residues; Hexaclorobenzane (HCB), aldrin, glyphosate, endosulfan are all below EU MRL values in the treated tubers. On the other hand, only emamectin, paraquat and dichlorvos were detected in the untreated (control) with the respective values of $0.508,0.365$ and $0.023 \mathrm{mg} / \mathrm{kg}$, which are also higher than the EU MRL values; whereas the rest of the residues were not detected.

Table 5: The result of Pesticide Residues in $D$. rotundata

\begin{tabular}{cccc}
\hline S/N & Residues & \multicolumn{2}{c}{ Groups } \\
\cline { 2 - 3 } 1 & Chlorpyrifos & Control(mg/kg) & Test (mg/kg) \\
2 & Endosulfan & ND & 0.072 \\
3 & DDD & ND & 0.01 \\
4 & Chlordane & ND $/ \mathbf{k g})$ & 0.333 \\
5 & t-nonachlor & ND & 0.111 \\
6 & Aldrin & ND & $0.071^{*}$ \\
7 & Hexaclorobenzane & ND & $0.05^{*}$ \\
8 & Paraquat & 0.365 & 0.001 \\
9 & Glyphosate & ND & 0.003 \\
10 & Dichlorvos & 0.023 & 0.298 \\
11 & Emamectin & 0.508 & 0.001 \\
\hline
\end{tabular}

* Indicates EU MRL limit of analytical determination (or default value); ND = Not Detected.

The presence of residues in the untreated tubers can be suggested to be from the soil or as a result of previous pesticides application by the farmers (since some of these pesticides are persistent in the environment and plants). From this result, it can be suggested that consumption of yam tubers treated with perfect killer insecticide are unsafe, due to the fact that some residues were detected at concentrations higher than EU MRLs which may lead to various pesticide-associated diseases. This result is in concordance with that of Ogah et al. (2011) that reported the contamination of the food chain with residues of organochloride pesticides (including aldrin, dichloran, endosulfan, lindane, dieldrin etc.) in maize sold at markets in Nigeria and that some exceeded safety levels with probable detrimental consequences on human health. Similarly, Wumbei et al. (2018) also detected about eleven (11) residues in yam tubers produced in Ghana; however, the detected values were all below EU MRLs. Another study by Wumbei et al. (2019) also revealed that yam tubers are contaminated with multiple pesticide residues, including glyphosate, at levels below the EU MRL of the pesticides and generally with no food safety risk. In India, pesticides such as endosulfan, mancozeb, methyl parathion, monocrotophos, cypermethrin, isoproturon, chlorpyrifos, malathion, carbendazim, butachlor, quinalphos, copper oxychloride, and dichlorvos have been reported to be the most consumed in vegetables, fruits and food grains (India for Safe Food, 2019).

\section{Conclusion}

The result of this study suggested that Perfect killer insecticide is a combination of many pesticides; hence treatment of yam tubers with it results in accumulation of the insecticide residues, which enhanced germination and conferred adverse effects on some growth parameters and proximate compositions of the plant but has no effect on chlorophylls. The pesticide offered protective measures against microbial attack thereby preventing postharvest spoilage of tubers after long period of storage. People who depend majorly on these tubers as a source of nutrient are at high risk of pesticides exposure and the associated diseases due to the high values of some detected residues which may accumulate to toxicity levels over time. Further studies are therefore needed to investigate the toxicity on plants and animals at varying concentrations of 
Determination of Pesticide Residues in Yam (Dioscorea rotundata) Tubers Grown with Perfect Killer Insecticide, and their Effects on Growth Indices and Proximate Composition

Perfect killer insecticide, and effects on oxidative stress enzymes and biochemical indices using animal models.

\section{References}

1. Aboagye-Nuamah, F., Offei, S.K., Cornelius, E.W. and Bancroft, R.D. (2005). Severity of Spoilage Storage Rots of White Yam (Discorea rotundata Poir). Annals of Applied Biology, 147(2);182-190.

2. Adeyeye, A. and Osibanjo, O. (1999). Residues of Organochlorine Pesticides in Fruits, Vegetables and Tubers from Nigerian Markets. Sci. Total Environ, 231(2-3), 227- 233.

3. Andres, C., AdeOluwa, O.O. and Bhullar, G.S. (2017). Yam (Dioscorea spp.). In Brian T., Brian, G.M. and Denis, J.M. (Editors in Chief). Encyclopedia of Applied Plant Sciences. Waltham, MA: Academic Press, 3:pp.435441.

4. AOAC. (1984). Official Methods of Analysis of the Association of Official Analytical Chemists. 14th edition. Washington, DC, Association of Official Analytical Chemists.

5. AOAC. (1990). Association of Analytical Chemistry Method for Chemiscal Analysis: 2217- 2218.

6. Arnon, D.I. (1949). Copper Enzymes in Isolated Chloroplasts. Polyphenoloxidase in Beta vulgaris.

Plant Physiol., 24:1-15.

7. Baah, F.D., Maziya-Dixon, B., Asiedu, R., Oduro, I. and Ellis, W.O. (2009). Nutritional and Biochemical Composition of D. alata (Discorea spp) Tubers. Journal of Food, Agriculture and Environment, 7(2);373-378.

8. Babu, H.S., P. Jayaraman and P. Aarthy, (2010). Screening of Ach Ease Inhibition in Blood and Plasma and Brain of Wistar Rats by Neurella D (Combination Pesticide). Int. J. Pharma Bio Sci., 1:574-578.

9. Banke, I.S., A.S. Folorunsho, B. Mohammed, S.M. Musa, O. Charles and A.J. Olusegun. (2014). Effects of Melatonin on Changes in Cognitive Performances and Brain Malondialdehyde Concentration Induced by SubChronic Co-Administration of Chlorpyrifos and Cypermethrin in Male Wister Rats. Asian Pac. J. Trop. Biomed., 4:318-323.

10. Barry, P., Young, A. J. and Briton, G. (1990). Photodestruction in Higher Plants by Herbicide Action. $J$. Exp. Bot., 41:123-126.

11. Claudius-Cole, A.O., Kenyon, L. and Coyne, L. (2017). Effect f Pre-Plant Treatments f Yam (Dioscorea rotundata) Setts on the Production of Healthy Seed Yam, Seed Yam Storage and Consecutive Ware Tuber Production. Journal of Agriculture and Rural Development in the Tropics and Subtropics, 118(2):297-306.

12. Coursey, D.G. (1967). Yams. Longmans Green, London.

13. Fuerst, E. P. and Norman, M. A. (1991). Interactions of Herbicides with Photosynthetic Electron Transport. Weed Sci., 39:458-464

14. Grewal1, A.S., Singla, A., Pradeep, K. and Jagdeep, S.D. (2017). Pesticide Residues in Food Grains, Vegetables and Fruits: A Hazard to Human Health. J. Med. Chem. Toxicol. 2(1): 1- 7 .

15. India for Safe Food (2019). http:// indiaforsafefood.in.

16. International Institute for Tropical Agriculture (IITA). (2009). Yam (Dioscorea species).

17. IPCS (International Programme on Chemical Safety). (1990). Environmental Health Criteria 97, Deltamethrin. World Health Organization, Geneva, IPCS INCHEM (1975). Retrieved on October 24, 2012.
18. Ki-Hyun, K., Ehsanul, K. and Shamin, A.J. (2017). Exposure to Pesticides and the Associated Human Health Effects. Science of the Total Environment, 575:525-535.

19. Lape, M. I. and Treche, S. (1994). Nutritional Quality of Yam (Dioscorea dumentorum and D. rotundata) Flours for Growing Rats. Journal of the Science of Food and Agriculture, 66:447-455.

20. Maikasuwa, M. A. and Ala, A. L. (2013). Determination of Profitability and Resource-Use Efficiency of Yam Production by Women in Bosso Local Government Area of Niger State, Nigeria. European Scientific Journal, 9(16):196-205.

21. Moore, M. T. and Kroger, R. (2010). Effect of three Insecticides and two Herbicides on Rice (Oryza sativa) Seedling Germination and Growth. Arch. Environ. Contam. Toxicol., $\quad \mathbf{5 9 : 5 7 4 - 5 8 1 .}$

22. Ogah, C.O., Coker, H.B. and Adepoju-Bello, A.A. (2011) Organophosphate and Carbamate Pesticide Residues in Beans from Markets in Lagos State, Nigeria. J. Inn. Res. Eng. Sciences, 2(1): 50-59.

23. Oguntade, A.E., Thompson, O.A. and Ige, T. (2010) Economics of Seed Yam Production Using Minisett Technique in Oyo State, Nigeria. Field Actions Science Reports [Online].

24. Osiru, D.S.O. and Hahn, S.K. (1994). Effects of Mulching Materials on the Growth, development and Yield of White Yam. African Crop Science Journal, 2(2):pp153-160.

25. Parween, T., Jan, S., Mahmooduzzafar and Fatma T. (2011b) Assessing the Impact of Chlorpyrifos on Growth Photosynthetic Pigments and Yield in Vigna radiata L. at Different Phenological Stages. African Journal of Agricultural Research, 6(19), pp. 4432- 4440.

26. Parween, T., Jan, S., Mahmooduzzafar and Fatma, T. (2011a). Alteration in nitrogen metabolism and plant growth during different developmental stages of green gram (Vigna radiata L.) in response to chlorpyrifos. Acta Physiol. Plant, 33:2321-2328.

27. Parween. T, Sumira, J., Sumira, M., Tasneem, F. and Zahid, H.S. (2016) Selective Effect of Pesticides on Plant - A Review. Critical Reviews in Food Science and Nutrition, $\mathbf{5 6}$ (1):160-179. Rajashekhar, N., Prakasha and Murthy, T. C. S. (2012). Seed germination and physiological behavior of Maize (cv. Nac-6002) seedlings under abiotic stress (Pendimethalin) condition. Asian J. Crop Sci. 4(2):80-85.

28. Rehab, E.M. and El-Said, S. (2016). Side Effects of Certain Pesticides on Chlorophyll and Carotenoids Contents in Leaves of Maize and Tomato Plants. Middle East J. Agric. Res., 5(4): 566-571.

29. Verter, N. and Bečvařova, V. (2015). An Analysis of Yam Production in Nigeria. Acta Universitatis Agriculturae et Silviculturae Mendelianae Brunensis, 63(2): 659-665.

30. Vishnu, S.S., Nandjee, K., and. Pathak, R.N. (2015). Effect of Chemical Pesticides on Chlorophyll Content of Vicia faba L. Journal of Chemistry and Chemical Sciences, $\mathbf{5}(1): 1-4$.

31. Wumbe, A., Senaeve, D., Houbraken, M. and Spanoghe, P. (2018). Pesticides Residue Analysis in Yam from Selected Markets across Ghana and Belgium: an evaluation of the QUECHERS method. International Journal of Food Contamination, 5(4):1-10

32. Wumbei, A., Bawa, J.K.A., Akudugu, M.A. and Spanoghe, P. (2019). Absence of effects of herbicides Use on Yam Rots: A Case Study in Wulensi, Ghana. Agriculture, 9(5); 9.

33. Yadav, I.C., Devi, N.L. (2017). Pesticides Classification and Its Impact on Human and Environment. Environ. Sci. \& $\begin{array}{lll}\text { Engg. } & 6: & \text { Toxicology. }\end{array}$ 